\title{
The role of noninvasive ventilation in patients with "do not intubate" order in the emergency setting
}

\author{
M Vilaça ${ }^{1 *}$, C Dias $^{2}$, I Aragão $^{3}$, G Campello ${ }^{3}$ \\ From ESICM LIVES 2015 \\ Berlin, Germany. 3-7 October 2015
}

\section{Introduction}

Noninvasive ventilation (NIV) has been increasingly used in patients with a "do not intubate" order (DNI). In this group of patients the use of NIV in intensive care units was associated with no decrease in health-related quality of life (HRQOL). Its impact on the clinical and HRQOL in the emergency setting is still unknown as is its utility in symptom relief in the end-of-life care.

\section{Objectives}

To evaluate the impact of the use of NIV in the outcome and HRQOL in patients with DNI order admitted to the emergency room.

\section{Methods}

Prospective cohort study of all patients who receive NIV for acute or acute-on-chronic respiratory failure with DNI order admitted to the emergency room of a tertiary care, university-affiliated, 600-bed hospital between January and December 2014. Patients were divided in two groups: those who had a DNI order in the context of withhold therapy decision and those in whom all treatment, including NIV was provided for symptom relief. For HRQOL evaluation SF-12 was used. This evaluation was made only in the first group of patients. Long-term outcome was evaluated at 90 days after hospital discharge by a telephone interview.

\section{Results}

During the study period 1727 patients were admitted to the emergency room, 243 were included in the study and $70(29 \%)$ had a "do-not-intubate order", of those 29 (41\%) received NIV for symptom relief. The median age was 82 years in the first group and 79 years in the second

${ }^{1}$ Medicine Integrated Master (MIM), Instituto de Ciência Biomédicas Abel Salazar, Porto, Portugal

Full list of author information is available at the end of the article $(\mathrm{p}=0,299)$. Active cancer $[7 \%(\mathrm{n}=10)$ vs $35 \%(\mathrm{n}=3)$, $\mathrm{p}=0,004]$ and neuromuscular diseases $[0 \%$ vs. $17 \%$ $(\mathrm{n}=5), \mathrm{p}=0,010]$ were more prevalent in the group undergoing symptom relief treatment. NIV was stopped in $20 \%(\mathrm{n}=8)$ of patients in the first group and in $59 \%$ $(\mathrm{n}=17)$ in the second group, due to lack of clinical benefit $(\mathrm{p}<0.001)$. The hospital mortality rate was $37 \%$ $(\mathrm{n}=15)$ in the first group and $86 \%(\mathrm{n}=25)$ in the symptom relief group $(\mathrm{p}<0,001)$. Among the group of patients discharged from hospital, $24 \%(n=6)$ of the first group and all patients from the second group were dead at the point long-term outcome evaluation. No significant decline in HRQOL was observed at 90 days when compared to baseline.

\section{Conclusions}

A DNI order was present in $29 \%$ of patients who received NIV for acute or acute-on-chronic respiratory failure in the emergency room. Long-term outcome

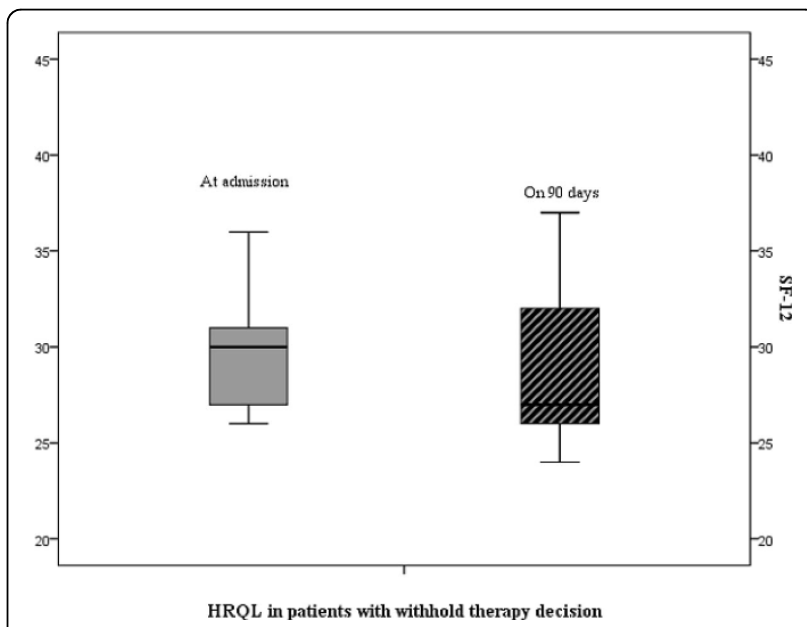

Figure $1 \mathrm{HRQOL}$ in patients with withhold therapy decision. 
translated to a $49 \%$ survival rate in the group of patients with a DNI order in whom NIV was used as a treatment with no decrease in HRQOL compared to baseline. NIV did not provide significant symptom relief in more than half of the patients in whom it was used for that purpose.

\section{Authors' details}

'Medicine Integrated Master (MIM), Instituto de Ciência Biomédicas Abel Salazar, Porto, Portugal. ${ }^{2}$ Information Sciences and Decision on Health Department (CIDES), Faculdade de Medicina da Universidade do Porto, Porto, Portugal. ${ }^{3}$ Intensive Care Unit (UCIP)- Centro Hospitalar do Porto, Porto, Portugal.

Published: 1 October 2015

\section{Reference}

1. Azoulay $E$, et al: Noninvasive mechanical ventilation in patients having declined tracheal intubation. Intensive Care Med 2013, 39(2):292-301.

doi:10.1186/2197-425X-3-S1-A172

Cite this article as: Vilaça et al:: The role of noninvasive ventilation in patients with "do not intubate" order in the emergency setting. Intensive Care Medicine Experimental 2015 3(Suppl 1):A172.

\section{Submit your manuscript to a SpringerOpen ${ }^{\mathcal{O}}$ journal and benefit from:}

- Convenient online submission

- Rigorous peer review

- Immediate publication on acceptance

- Open access: articles freely available online

- High visibility within the field

- Retaining the copyright to your article 